\title{
Adoption of Supply Chain Model to Improve Terminal Device Distribution at Mobifone: Evidence from Vietnam
}

\author{
Submitted 21/12/20, $1^{\text {st }}$ revision 28/01/21, $2^{\text {nd }}$ revision 20/02/21, accepted 20/03/21
}

\author{
Huynh Thi Thu Suong ${ }^{1}$, Tiêu Vân Trang ${ }^{2}$
}

\begin{abstract}
:
Purpose: This research explores and clarifies the distribution of terminal devices at Mobifone company $(M B C)$. From the theory of supply chain $(S C)$, the nature and performance of the $S C$, and the principles of SC construction and operation, the article conducts research on how to complete the construction of SC's terminal device at MBC aims to help MBC leaders identify the advantages and limitations in their existing $S C$ as well as $M B C$ 's distribution. From that, MBC managers have the property strategy in investing resources to continue improving the distribution of terminal devices in their SC.

Methodology/Approach: A qualitative method with specialized technical expertise and group discussion helps design a questionnaire surveying 132 head store managers at MBC. Finally, using descriptive statistical techniques, primary data is processed on SPSS 20.0 software to measure the factors related to terminal SC construction at MBC.

Findings: The findings show that the core activities of the construction of SC's terminal device at $M B C$ are quite suitable. However, it still has some outstanding limitations; there is no department in charge of the overall planning. From the theory of supply chain (SC), the nature and performance of the SC, and the principles of SC construction and operation, the article researches how to complete the construction of SC's terminal device at Mobifone Company $(M B C)$ aims to help MBC leaders identify the advantages and limitations in their existing SC as well as $M B C^{\prime}$ 's distribution.

Originality/Value: There have been many studies on the supply chain, but most studies only on the relationship of the chain or the chain's effectiveness in many different industries. However, research on the supply chain structure model in the retail sector about terminal equipment in the telecommunications industry has not. Summing up to work out a joint plan across the SC to connect each actor in the SC into a cohesive link to make the SC operation smooth and continuous.
\end{abstract}

Keywords: Supply chain model, terminal device, mobifone distribution, Vietnam.

JEL Classification: M30, M31, Q55.

Paper type: Research paper.

\footnotetext{
${ }^{1}$ Faculty of Business Administration, University of Finance - Marketing (UFM), Vietnam, huynhthusuong@ufm.edu.vn

${ }^{2}$ Faculty of Business Administration, University of Finance - Marketing (UFM), Vietnam, tvtrang@ufm.edu.vn
} 


\section{Introduction}

SC is an important part of an enterprise's production and business activities and always receives the attention of leaders. However, many businesses still do not understand SC's operation, and there is often confusion between SC and distribution chain or logistics. This leads to inadequate attention and investment for SC activities, application of SC theories are still sketchy and not thorough, leading to improper and unreliable SC activities cohesion with other parts and bring high efficiency for businesses. Facing the trend of customers using the Internet (via 4G, 5G telecommunication bands), the telecom network operators in the world have been striving to provide terminal packages to increase the average revenue per customer and keep customers. This is also a new source of revenue for telecommunication operators in Vietnam and all telecommunication operators in the world to replace, offset the decline from traditional telephone services when the market becomes saturated. To promote the brand image, MBC actively serves and takes care of customers, contributing to increasing its terminal business revenue, aiming to build and operate a terminal retail chain with benefits about brand and telecommunication services.

Therefore, it is essential to focus on developing telecommunication packages with terminal equipment. Building terminal SC in the context of fierce competition in telecommunication services, with young experience on $\mathrm{SC}$ and urgent requirement of terminal SC construction time. By implementing the actual terminal SC from the end of 2015, the SC terminal operation at MBC has revealed many inadequacies and limitations in existence. It is necessary to look at the analysis thoroughly to improve further the construction of an effective terminal SC for MBC. In the very competitive period of supply chain management, it has become apparent that the supply chain model needs to be handled efficiently to gain and maintain a competitive advantage (Colicchia and Strozzi, 2012). Additionally, unpredictabilities and threats (e.g., transport risks) have also increased with supply chains' globalization (Baryannis et al., 2019; Behzadi, O'Sullivan, Olsen, and Zhang, 2018). The tendency is derived from the fact that the unpredictability and threats emerge from strategies for the effectiveness of supply chains in the contemporary period, as Revilla and Saenz (2017) stated. These techniques comprise lean manufacturing, stock, a smaller number of vendors, centralized distribution, globalization advantages exploitation, outsourcing, and digital technology use.

\section{Literature Review}

\subsection{Supply Chain}

SC understands the connection between suppliers, customers, manufacturers, and service-providing organizations related to business processes (Russell and Taylor, 2014). An SC consists of a journey of linkage among the factors in which there are the 3 core activities, including: (i) Supply: how to focus on purchasing activities? Where and when raw materials are supplied to serve the production process 
effectively; (ii) Production: the process of conversion into finished products of the raw materials; (iii) Distribution: the process of confirming whether the goods are delivered to end customers in a timely and effective way via distribution grid, warehousing, retail (DeTienne et al., 2015). In practice, depending on the business strategy and the characteristics of each industry, which factors will participate in the chain regulation is very important. This means that suppliers or manufacturers, or distributors are involved as chain regulators. Some typical SC models are as follows (Christopher, 2005). Using SCOR to analyze and evaluate any SC, there are 4 activities:

Planning: Supply chain planning is a combination of resources to optimize the delivery of products, services, and information from suppliers to customers, balancing supply and demand. These include the main activities, Demand Forecasting, General Planning, Product Pricing, Inventory Management.

Source sourcing: The stages in this process include the activities needed to concentrate input materials to produce products or services. Main activities include Purchasing (Purchasing, Purchasing, Managing Sales, Selecting Sales, Negotiating contracts, Managing Contracts), Selling and taking debt.

Manufacturing: To develop and build products and services created by the supply chain, this process requires the following stages, product design, production management, development, and general operator.

Including main activities: Product design, Production scheduling, Facility management.

Distribution: This stage includes activities associated with receiving orders and delivering products to customers. The three stages understood were managing, delivering, and handling returned goods. These factors are the link between the businesses participating in the supply chain. Main activities include Order management (Single order entry, Automation of order management, Display of order status information, Use of associated order management systems, Distribution plan (Direct distribution, Distribution according to the predetermined roadmap, Distribution source).

\subsection{Supply Chain Model}

\subsubsection{Definition of SC's Mobifone Industry}

Terminal retail SC is the actor or channel member in a certain industry. They are suppliers, intermediaries, and end consumers in the mobile telephony industry. The manufacturers of cell phones are easy to recognize because they manufactured branded products. Many Chinese original equipment manufacturers distribute cell phones under other brands as they are not allowed to trade iPhones are not mentioned in this paper (Magrath and Hardy, 1989). The intermediaries are the bridge between producers and end-users. Operators, distributors, and retailers are three types of intermediaries in the Vietnam mobile phone market (Bucklin, 1966). Based on the size and regional reach, distributors are split into national agents, provincial distributors, and local dealers. Local convenience stores, home appliance stores, phone stores, supermarkets are all retailers. Another form of intermediation is known 
as specialist mediation in channel documentation that carries out a particular flow and is not normally deeply involved in the main business shown by the product being sold. Finance and insurance companies, banks, advertising agents, logistics and shipping companies, IT, and marketing firms. End-users may play a part in channel documentation collectively as they often conduct assembly of such channel flows for computers. The intermediaries and manufacturers' channel strategy is influenced by the service outcomes (place, time, lot sizes) demanded by the end-consumers.

\subsubsection{The Relation is the Keyword in the Theory of Network}

According to Yeniyurt et al. (2013), relations between a company and a client, a supplier, or another organization, are defined as interaction patterns and reciprocal conditions in behaviors. Also, the relationship substances consist of agent link (the link between agents of the two firms), action link (behaviors connections between the two firms), and resource bonds (the mutual adaptation of firm resources). There are three facets of relationships. Firstly, it is a tool to achieve productivity and creativity and to affect others. Secondly, relationships are the most valuable assets of an organization since they can not access other people's resources, obtain the supplies they need, or solve their clients' problems, generating profits. Thirdly, it is difficult to manage relationships because they often have present or future issues. Chain stores have been strong players at the retail stage. The chain retailers have three kinds: supermarkets, specialty phones, and home appliance chain stores.

SC integrates three or more core components in terms of transaction operation, integration, and relationship (Suong, 2012). There is a continuous form of relationships in each integration level: (i) Transaction is commonly seen as trading goods, services, or finances-a transaction link in the exchange of discrete value, especially price (Bäckstrand, 2007). Commercial transactions related to price bargaining when dealing with a supplier is a competitor relationship to increase an $\mathrm{SC}$ member's profit; (ii) Collaborating is interacting or partnering with a partner. To put it differently, cooperation can benefit all parties within SC. The categories of integrated relationships are competitor or nonrival partnerships and producer-supplier partnerships (Harland, 1996); (iii) A form of association is often considered a combination of two entities into one entity for business progression between two actors, an association relationship consisting of vertical linking, acquisitions, and joint ventures, and full ownership. or consolidation (Bintoro et at., 2015)

\subsubsection{Types of Distribution}

As mentioned above, department stores/supermarkets, especially chain stores, home appliance chain stores, and local shops, are four categories. In the early stages of mobile telephone delivery, local stores are the ones that dominate. Normally, individuals operate these stores. The benefit of focusing on a single market was creating an industrial platform where stores were active rivals, and market knowledge was flowing rapidly. Without visiting several scattered stores, shoppers can go around and make some price comparisons. Flexibility and personal relationships with customers were the strong points of local businesses. Retail prices should be freely modified in compliance with markets. In general, they establish good ties with old 
clients to get new clients. Its reliability was its weakness. Consumers cannot expect the shops always to be there. Worse still, several shops have been dealing with counterfeit and outdated phones which have been renovated as new and smuggled ones. Concerning SC at MSC, the end-users role decides the success of the retailer as $\mathrm{MBC}$. Therefore, MBC struggles to innovate and improve all their deficit distribution to compete with other competitors within the industry.

The requirement and the capability to handle connections in the supply chain network, according to Chen and Fung (2013), is very much related to supply chain management. Current supply chain literature has a great deal of emphasis on integrated ties with manufacturers. A fully integrated supply chain can increase and enhance general supply chain efficiency through high-quality relationships. An essential level with providers (Tsai and Hung, 2016) since the suppliers play a major role and contribute to improved SC effectiveness and reactivity.

Buyer-supplier cooperation for business progress leads to stronger innovation results, as mentioned by Sáenz, Revilla, and Knoppen (2014). According to Craighead, Hult, and Ketchen (2009), outcome variations are due to providers' strong or weak dedication to their ability to develop expertise. The two key factors which have decided the achievement of SC innovation objectives are integration and cooperation with suppliers (Flynn, Huo, and Zhao, 2010). Innovation success is directly influenced by factors such as buyer-supplier relationships, supplier engagement in innovation, manners, and attitude towards co-innovation (Yeniyurt, Henke, and Yalcinkaya, 2013). The threats, training, and benefits sharing between buyers and providers also affect innovation processes (Johnsen, 2016).

\section{Structure of SC's MBC}

There are various actors in SC, decided by which industry. The three main actors in the SC dairy industry, including producers and dealers, retailers, and end-user are described as follows. Due to their respective strengths and limitations concerning environmental changes, the national distributors have lost their advantage over the provincial/performance distributors. In tier 3rd and 4th cities, local distributors will remain in place to supply for fragmented markets. There are more provincial distributors while local ones' total numbers fluctuate (Joe et al., 2009).

\section{Research Data and Research Methodology}

\subsection{Research Data}

This research aims for the SCOR model buyer-supplier relationship, SC effect, and competitive advantage to be proposed and empirically tested through the review of surveyed data at MBC's major stores. MBC has been chosen as an integral part of its retail growth as it is a standard case of a terminal. As a research tool for the topic research, a questionnaire was utilized, and the corresponding entries of previous researches were applied-tables 1 to 5 display the descriptions of all structures and 
their respective objects. For example, Kwak et al. (2018) adopted five products for the active supply chain size. Five products were tailored to the relationship between buyer and supplier from Jajja, Kannan, Brah, and Hassan (2017).

Figure 1. Compare two models of structure and multiple distributor model

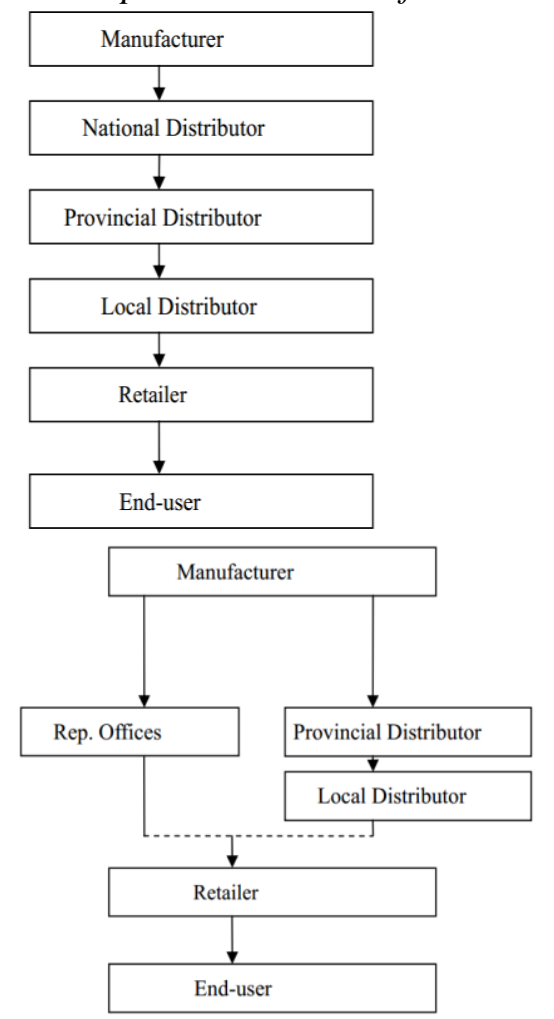

Source: Quality research by authors, 2020.

To alleviate degradation problems caused by the range constraints (Oh and Rhee, 2008), a five-point Likert scale in place of a five-point scale was applied with 1-full disagreement to a 5 -full agreement. Data from Vietnam MBC supply chain managers have been obtained. In compliance with the previous research by Grobler and Grubner (2006); Flynn, Huo, and Zhao (2010); Jajja, Kannan, Brah, and Hassan (2017), due to the lack of available Vietnam retail databases, non-probability sampling was utilized. The questionnaires were conducted and circulated among relevant managers who are in charge of procurement and inventory control. There have been a total of 122 correct answers, of which 132 answers have ample for inclusion in the study.

\subsection{Research Methodology}

Qualitative research methods through statistical techniques, analysis, and synthesis of secondary data of MBC in the terminal supply chain sector were used. An in-depth interview with leading experts, senior managers at $\mathrm{MBC}$ on issues during building 
SC terminal equipment at MBC. Using group discussion techniques with the Corporation and regional companies (being branches) to distribute sales, thereby forming ideas, shaping the design of survey questionnaires. Survey subjects are direct operational administrators, including 132 Head Stores at MBC service shops, to verify the implementation of terminal supply chain construction at $\mathrm{MBC}$, preliminary data. Levels are processed on SPSS 20.0 by descriptive statistics to measure the level of attainment of the factors related to SC terminals' construction at MBC.

\section{Research Results}

\subsection{Competitive Situation in the Terminal Retail Industry}

The largest chain of retail terminals in Vietnam in terms of scale, products, and aftersales services is Mobile World (653 stores, 35\% market share), Telecommunications A (422 stores). With 13\% market share), FPT Shop (339 stores, 16\% market share). Retailers of electronics, electronics, and telecommunications such as Tran Anh and Nguyen Kim also constantly expanded the system and began to make business strategies such as Nguyen Kim joint venture with Central Group partner of Thailand. Lan (accounting for $11 \%$ market share). Viettel: established a retail system (Viettel Store) specializing in trading terminal devices in the telecommunication store system. 
Vinaphone and Viettel are the only two carriers that distribute Apple products.

\subsection{Retail Store Operation Model}

Figure 2. MobiFone terminal retail chain operation model

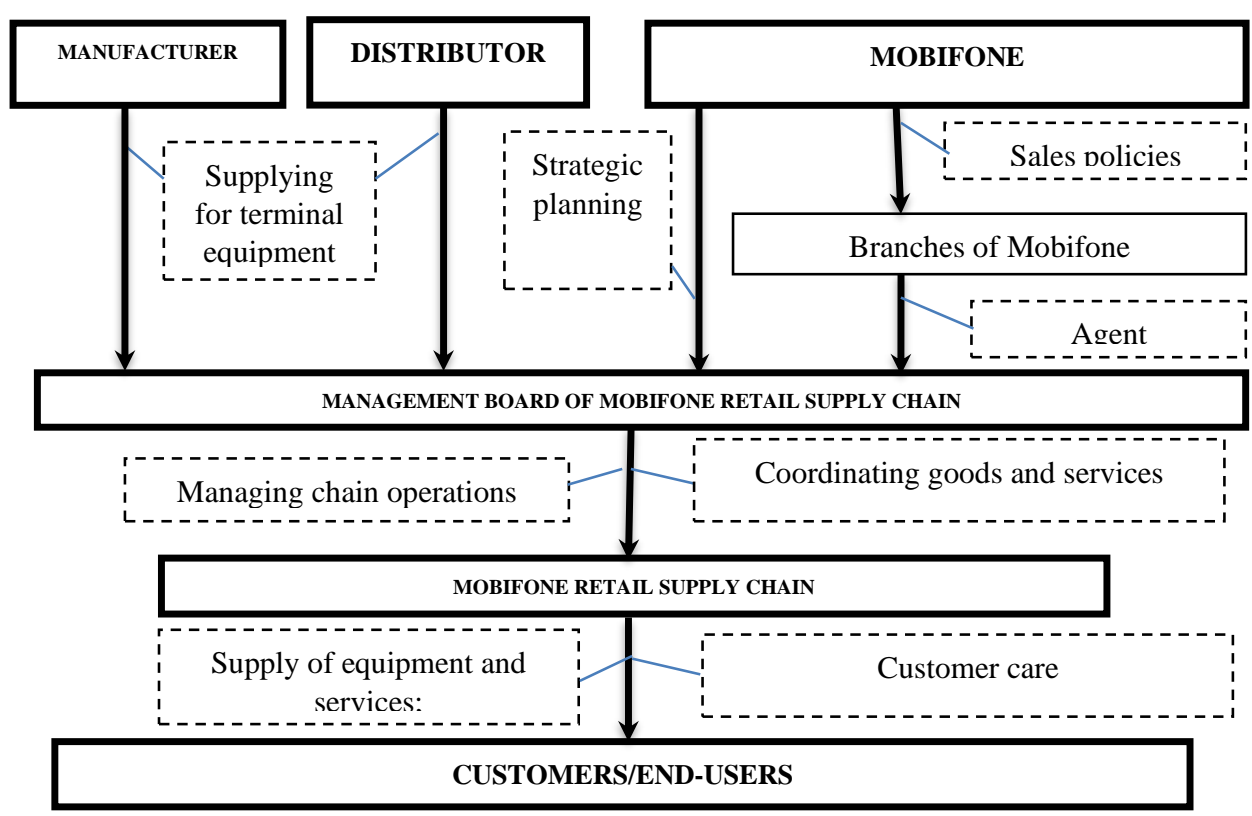

Source: Synthesized from Sales Department of MBC, 2020.

The MBC terminal retail store model is built as follows: Establishing a retail chain board that is responsible for managing and managing the entire supply chain, coordinating goods and services to customers. The chain of stores includes 122 stores nationwide. Relevant MBC departments and agencies, especially regional companies, work together to implement the process to ensure business continuity. Based on MBC terminal retail stores' model, the MBC retail chain unit is considered the central 
operating unit of the entire SC, but this unit is not as complete as the lack of apparatus.

Department of general planning and control board.

\subsection{Evaluation of Terminal Construction SC Activities at MBC}

Table 2. Assessment of SC planning work

\begin{tabular}{lcccc}
\multicolumn{1}{c}{ Content } & Min & Max & Mean & $\begin{array}{c}\text { Std } \\
\text { Deviation }\end{array}$ \\
\hline $\begin{array}{l}\text { Carry out the forecast of demand at the } \\
\text { store }\end{array}$ & 1 & 3 & 2.21 & .683 \\
$\begin{array}{l}\text { Deploying the promotions timely } \\
\begin{array}{l}\text { Valuation of terminal products is a } \\
\text { high-end product line }\end{array}\end{array}$ & 1 & 3 & 2.52 & .518 \\
$\quad$ Storage preservation work & 3 & 5 & 3.08 & .711 \\
\hline
\end{tabular}

Source: Results of authors' primary data processing, 2020.

\subsubsection{Regarding Planning to the SCOR Model}

With the above comment results, the forecast of demand at the store is still poor because most of the chief stores, when making the forecast, still depend on the subjectivity, most of them do not have much experience on demand forecasts because they specialize in customer service before. Also, the implementation of promotions is poor: most of the promotions are issued by MBC Sales and Marketing Department; at the store, the program is only implemented, but there are still many difficulties. Such as the lack of synchronous coordination between MBC departments and shops, promotions are not suitable with the actual situation in the locality and not timely. Also, warehouse preservation is highly appreciated because all stores have implemented warehouse storage processes very professionally for many years.

Table 3. Evaluation of Sourcing Activities

\begin{tabular}{lrrrr}
\multicolumn{1}{c}{ Content } & Min & Max & Mean & Std Deviation \\
\hline $\begin{array}{l}\text { Criteria for selecting suppliers to have a competitive sales } \\
\text { policy }\end{array}$ & 2 & 4 & 2.49 & .518 \\
$\begin{array}{l}\text { Process delivery, facilities, and delivery equipment consistent } \\
\text { with the store }\end{array}$ & 3 & 5 & 4.16 & .761 \\
$\begin{array}{l}\text { Diverse products suitable to customer needs } \\
\text { Organizing sales science, utilities, and convenience }\end{array}$ & 2 & 5 & 3.48 & .695 \\
& 3 & 5 & 4.42 & .587 \\
Sales discount policy & 2 & 3 & 2.31 & .465 \\
The form of payment is applied & 1 & 3 & 2.20 & .712 \\
\hline
\end{tabular}

Source: Results of authors' primary data processing, 2020.

\subsubsection{Regarding Sourcing to the SCOR Model}

The survey results show that: (i) The payment factor applied to customers is the lowest. According to a Sales and Marketing Department's research survey, retail sales of terminal equipment in the Vietnam market always account for over $50 \%$ due to the deferred payment policy applied to customers. However, at present, MobiFone is only 
a form of deferred payment through the commitment to use the package for a certain period and requires customers to pay a deposit when buying equipment. With this policy, the head stores rated it poorly because of the high deposit amount. (ii) Sales discount: MobiFone has a sales promotion policy for customers, but it is not significant and is always deducted from the additional service costs when customers use the package with the terminal (for example, giving) internet access capacity 3G, 4G). This makes customers feel and satisfied with the discount that the company offers them. (iii) With the failure to sign distribution agreements with key manufacturers such as Apple, Samsung loses the price competitive advantage because when the distribution agreement is reached, the manufacturer has a good policy. serve the business activities of both parties. (iv) Factors: The delivery process, facilities, and delivery tools are highly appreciated because MBC always pays special attention to investing in equipment to serve long-term and professional business.

Table 4. Assessment of production activities of the company

\begin{tabular}{lcccc}
\hline \multicolumn{1}{c}{ Content } & Min & Max & Mean & Std Deviation \\
\hline $\begin{array}{l}\text { Designing mobile subscription packages according to } \\
\text { the terminal equipment }\end{array}$ & 1 & 3 & 2.19 & .786 \\
$\begin{array}{l}\text { The process of coordinating the integration of product } \\
\text { packages for customers }\end{array}$ & 2 & 3 & 2.46 & .500 \\
$\begin{array}{l}\text { The variety of packages suitable for a variety of } \\
\text { terminals }\end{array}$ & 1 & 3 & 2.06 & .816 \\
Preparatory work for freight forwarding & 2 & 5 & 3.24 & .531 \\
\hline
\end{tabular}

Source: Results of authors' primary data processing, 2020.

\subsubsection{Regarding Production Activities to the SCOR Model}

Survey results show that the factors of package design and the diversity of packages are still poor: for the integrated packages for iPhone 8,11,12 and Samsung Galaxy S7/S7 Edge/ SG Z Flip, it has not attracted customers by the amount of money. Deposit or deposit is quite high compared to the product's price while there is a commitment to use the package for a certain period. The strength of the MBC terminal supply chain is the focus on exploiting the terminal integrated telecommunications services. However, up to now, the company has only integrated telecommunications service packages with two product lines that are too few (and this is a high-end equipment product line), not yet diversified, and suitable with the majority of customer needs. A weakness in product design is that all package products are designed by the Product Design Department of the Corporation; there is no coordination with distribution stores to capture customers' needs more closely. On the other hand, the preparation for delivery is highly appreciated because before launching the product, $\mathrm{MBC}$ always has a cautious preparation period from materials 
to marketing communications for the whole system.

Table 5. Evaluation of distribution activities of the company

\begin{tabular}{lcccr}
\hline \multicolumn{1}{c}{ Content } & Min & Max & Mean & Std Deviation \\
\hline Distribution channel system, agent & 3 & 5 & 4.40 & .046 \\
Order management & 3 & 5 & 4.16 & .068 \\
Implementation of the delivery process & 3 & 4 & 3.44 & .045 \\
Time to respond to complaints about return, warranty & 2 & 4 & 2.59 & .046 \\
\hline
\end{tabular}

Source: Results of authors' primary data processing, 2020.

\subsubsection{Regarding Distribution to the SCOR Model}

Most stores commented on the sales and the highly appreciated distribution system because this has been implemented professionally for many years. However, the time to respond to complaints about return, warranty of goods is lowest because this is the main process that has been implemented for service and customer care. Because many places are not suitable for the terminal retail business, the warranty period must be shorter for customers.

\subsection{Geneal Assessment of SC Construction Activities}

Table 6. Assessment of supply chain construction activities

\begin{tabular}{lcccc}
\multicolumn{1}{c}{ Content } & $\begin{array}{c}\text { Mi } \\
\mathbf{n}\end{array}$ & $\begin{array}{c}\text { Ma } \\
\mathbf{x}\end{array}$ & Mean & Std Deviation \\
\hline $\begin{array}{l}\text { Competence and experience of middle managers in supply } \\
\text { chain management }\end{array}$ & 2 & 5 & 2.92 & .663 \\
The staff of Transactors is suitable for retail terminal & 1 & 4 & 2.20 & .778 \\
Facilities, modern equipment at the store & 4 & 5 & 4.27 & .446 \\
Implement chain management IT program & 2 & 4 & 2.95 & .587 \\
\hline
\end{tabular}

Source: Results of authors' primary data processing, 2020.

After analyzing the actual implementation of terminal construction of SC at MBC and the results of the store assessment and assessment of SC construction activities, the study has drawn the achieved results and some limitations, exists in the construction of terminal SC at MBC, including achievements and limitations which need managers at MBC take note to conduct business.

\section{Conclusions and Discussions}

\subsection{Conclusions}

It can be reconfirmed that the SC terminal MBC has much potential for development. With the available resources of $\mathrm{MBC}$ in terms of infrastructure, professional staff, and advanced IT systems. MBC aims to optimize SC: SC operates smoothly to satisfy consumer expectations at the lowest operation cost. Simultaneously, a well-organized and frequently updated information system is important to help departments cooperate to respond quickly to the business environment's frequent and constant fluctuations. Present. To complete the construction of the terminal SC for MBC, it is 
the priority that MBC should focus on scaling up, affirming the brand, capturing and understanding partners and owners' trading practices. Dynamic and regular maintenance of transactional relationships with partners selectively, raising awareness of cooperation in SC. Also, it is necessary to continue to promote the existing strengths, especially the immediate and long-term solutions to overcome the existing limitations mentioned. To do so must surely operate SC equipment. At the end of MBC, there will be fast and effective development steps in the coming time.

\subsection{Discussions}

From the practice of building an SC terminal at $\mathrm{MBC}$, the following results were achieved:

(i) Building a closed warehouse management system: allowing real-time inventory tracking, Details to each warehouse, store, item. Simultaneously, it allows tracking the delivery and receipt plan and performing the warehousing, warehousing, warehousing, inventory operations. In particular, all costs are calculated and analyzed, and the cost of goods sold can be calculated and analyzed. Thus the net profit is analyzed.

According to safe inventory threshold, support alert function, goods nearly expired warranty, long-term inventory, obsolete goods. This is an important link, creating a premise for supply chain operations to meet inventory information requirements for the whole chain. Besides, the warehouse's preservation, the delivery process, facilities, and delivery tools at the store are highly appreciated and very professional. (ii) $\mathrm{MBC}$ has cooperated with reputable suppliers in the market to meet the requirements of supplying goods in large and stable quantities, enabling manufacturers to optimize their production plans. From there, it gives MBC a favorable price policy from suppliers.

(iii) Take advantage of the competitive advantage of products in the terminal retail market, a telecommunications network operator integrating packages with terminals to create a package of products committed to customer benefits. Simultaneously, the preparation for the distribution of goods is highly appreciated because before launching the product, $\mathrm{MBC}$ always has a cautious preparation period from materials to marketing communications for the whole system.

(iv) With a nationwide distribution network, operating the sales process and professional distribution channel management. Organizing scientific sales, giving customers the experience of products and dynamic service, simple and quick procedures.

(v) Facilities: taking advantage of the available system at 122 service shops in all provinces and cities nationwide. Follow the process of unifying and standardizing images and brands. This is a great advantage of the initial SC construction facility. (vi) Establishing the supply chain following the business strategy to meet customer needs. SC achieves the standard that suits customers' needs because MBC always focuses on investment and development, bringing the most convenient services to customers, partners, and business strategies based on competitive advantages.

(vii) Information Technology MBC has an IT Center that researches, manufactures, 
and develops new IT application software for units and customers inside and outside the Company; It Presides over research, develops, and deploys package technology solutions to meet the SC terminal requirements $\mathrm{MBC}$.

(viii) The highly-qualified management personnel and traders are trained in professional skills synchronously and professionally and have many years of experience in MobiFone services. The investment in facilities, modern equipment at modern shops, undertaken by the Marketing and Communications Department, is responsible for and carries out the uniformity of the whole SC brand image very professionally.

In addition to the results and successes achieved in the construction of SC terminals, MBC also has some limitations and shortcomings:

(i) There is no consensus and high consensus in SC leaders' determination to build SC terminals.

(ii) Components participating in SC activities in SC terminals' construction operate separately and independently, not yet connected into active units in the supply chain. MBC has established a specific and detailed role for each relevant unit in the SC system but has not yet formed a key unit to connect and deepen the units' chain into a unified block. Lack of a comprehensive planning department: At present, the Sales and Marketing Department only conducts the needs aggregation and forecasting from the distribution stores, but there is no overall planning department to follow. correct company strategy, manage promotions, inventory for the whole system.

(iii) The forecasting needs are carried out by a qualitative and subjective method of forecasting. Forecasts are made according to individual plans, lacking market information, leading to inaccurate forecasts.

(iv) The implementation of promotions is poor: most of the promotions are issued by the Sales and Marketing Department of the Corporation; at the store, the program is only implemented, but there are still many. such as the lack of synchronous coordination between the Corporation's divisions and shops, the promotion program has not been suitable with the actual situation in the locality and has not been timely.

(v) Criteria for selecting suppliers is limited: Firstly, lack of product recall criteria (defects, warranties) is essential in the selection of suppliers to serve customers. be the best. At the same time, control the supplier's commitment to product quality. Secondly, adding terms and conditions for the direct delivery of goods at distribution stores is quite important, contributing to reducing shipping costs for MBC, significantly affecting SC's effectiveness. Also, the failure to sign direct distribution cooperation with key manufacturers such as Apple, Samsung loses the price competitive advantage because when the distribution cooperation agreement is reached, the manufacturer has the main Good books for both parties' business activities.

(vi) Deploying the deferred payment/installment payment policy via VPBank's credit partner has not been implemented promptly, while this 
is one of the dominant sales opportunities in the terminal retail industry. MBC has a discount policy for sales to customers, but often many customers find it hard to feel this incentive because it is deducted from the additional service costs when customers use the package with the terminal.

(vii) The coordination of terminal integration package products has not been tight, not met well for sales distribution. Package products are not diverse (currently only integrated with high-end models such as iPhone 6, Samsung 6S Edge), and a critical issue to be aware of is the high deposit amount when you have an orange ending time using the package.

(viii) A complaint handling time of handling warranty complaints and defective products is not appropriate; it needs to shorten the time to ensure customer service quickly. The lowest response time for goods returns and warranty complaints is because this is the main process implemented to serve the main customer service and customer service. It is not suitable for a terminal retail business. Specifically, the warranty period must be shorter. For defective products manufactured by the manufacturer, they are entitled to exchange new products immediately for customers.

(ix) MBC's management team has no experience in construction and supply chain management activities. SC understanding of some regional leaders is not equal. The force of direct sales and existing tellers is not suitable for the terminal retail model. Building SC terminals right on the existing chain of stores have caused many difficulties and conflicts about the store manager's responsibility, i.e., increasing their responsibilities and obligations.

(x) Information technology: No overall plan for training, application development roadmap, and SC information sharing program and content have not been developed.

\section{References:}

Bäckstrand, J. 2007. Levels of Interaction in SC Relations. Jönköping Sweden: Thesis for Doctorate at Jönköping University.

Baryannis, G., Validi, S., Dani, S., Antoniou, G. 2019. Supply chain risk management and artificial intelligence: state of the art and future research directions. International Journal of Production Research, 57(7), 2179-2202.

Behzadi, G., O’Sullivan, M.J., Olsen, T.L., Zhang, A. 2018. Agribusiness supply chain riskmanagement: a review of quantitative decision models. Omega (Westport) $79,21-42$.

Bintoro, B.P.K., Simatupang, T.M., Putro, U.S. and Hermawan, P. 2015. Actors' interaction in the ERP implementation literature. Business Process Management Journal, 21(2), 222-249.

Bucklin, L.P. 1966. A Theory of Distribution Channel Structure. Institute of Business and Economic Research, University of California, Berkeley.

Chen, I.S., Fung, P.K., 2013. Relationship Configurations in the Apparel Supply Chain. 
Journal of Business \& Industrial Marketing, 28(4), 303-316.

Christopher, M., 2005. Logistics and Supply Chain Management: Creating Value-Adding Networks. Prentice Hall, Harlow.

Colicchia, C., Strozzi, F. 2012. Supply chain risk management: A new methodology for a systematic literature review. Supply Chain Management: An International Journal, 17(4), 403-418.

DeTienne, D., Golicic, S., Swink, M.L. 2015. Delivering successful supply chain innovations: lessons from CSCMP's supply chain innovation award winners. CSCMP Explores, 12(4), 1-14.

Flynn, B.B., Huo, B., Zhao, X. 2010. The impact of supply chain integration on performance: A contingency and configuration approach. Journal of Operations Management 28(1), 58-71.

Grobler, A., Grubner, A. 2006. An empirical model of the relationships between manufacturing capabilities. International Journal of Operations \& Production Management, 26(5), 458-85.

Harland, M. 1996. SC Management: Relationships, Chains, and Networks. British Journal of Management, 7(1), 63-80.

Jajja, M.S.S., Kannan, V.R., Brah, S.A., Hassan, S.Z. 2017. Linkages between firm innovation strategy, suppliers, product innovation, and business performance: insights from resource dependence theory. International Journal of Operations \& Production Management, 37(8), 1054-1075.

Joe, D. et al 2009. Principles Supply Chain Management - A Balanced Approach, SouthWestern Cengage Learning.

Johnson, M. 2016. Integrating the supply chain. International Journal of Physical Distribution \& Logistics Management, 1-31.

Kotler, P., et al. 2001. Principles of Marketing, 3rd European ed. Essex: Pearson Education Ltd.

Lee, H.L., Billington, C. 1995. The evolution of supply chain management models and practice at Hewlett-Packard. Interfaces, 25, 5, 41-63.

Magrath, J., Hardy G. 1989. A Strategic Paradigm for Predicting Manufacturer-Reseller Conflict. European Journal of Marketing, 23(2).

Mentzer, D. et al. 2001. Defining Supply Chain Management. Journal of Business Logistics, 22(2), 18.

Oh, J., Rhee, S. 2008. The influence of supplier capabilities and technology uncertainty on manufacturer-supplier collaboration: A study of the Korean automotive industry. International Journal of Operations \& Production Management, 28(6), 490-517.

Revilla, E., Saenz, M.J. 2017. The impact of risk management on the frequency of supply chain disruptions. a configurationally approach. International Journal of Operations \& Production Management, 37(5), 557-576.

Russell, R., Taylor, B. 2016. Operations and Supply Chain Management, 9th Edition. Willey \& Son Inc, USA.

Sáenz, M.J., Revilla, E., Knoppen, D. 2014. Absorptive capacity in buyer-supplier relationships: empirical evidence of its mediating role. Journal of Supply Chain Management, 50(2), 18-40.

Suong, H.T.T. 2012. Research on factors affecting the cooperation in the SC of Wooden furniture, the case researching the East Southern Region. HCMC, Vietnam: Thesis for Doctorate in University of Economics Ho Chi Minh City.

Suong, H.T.T., Tien, H.T. 2017 The practice of building a terminal supply chain for service enterprises and verifying at Mobifone. Journal of Industrial and Commerce 
Research, 8, 340-347.

Towill, D., Childerhouse, P., Disney, S. 2002. Integrating the automotive supply chain: where are we now? International Journal of Physical Distribution \& Logistics Management, 32(2), 79-95. https://doi.org/10.1108/09600030210421705.

Tsai, J.M., Hung, S.W. 2016. Supply Chain Relationship Quality and Performance in Technological Turbulence: An Artificial Neural Network Approach.

International Journal of Production Research, 54(9), 2757-2770.

Yeniyurt, S., Henke Jr., J.W., Yalcinkaya, G. 2013. A longitudinal analysis of supplier involvement in buyers' new product development: working relations, interdependence, co-innovation, and performance outcomes. Journal of the Academy of Marketing Science, 42(3), 29-308.

Yeniyurt, S., Henke Jr., J.W., Yalcinkaya, G. 2013. A longitudinal analysis of supplier involvement in buyers' new product development: working relations, interdependence, co-innovation, and performance outcomes. Journal of the Academy of Marketing Science, 42(3), 291-308. 